\title{
INJECTING DELETERIOUS SUBSTANCES INTO PIPELINES: A CASE STUDY OF A CONTAMINATION INCIDENT
}

\author{
PATRICIA A. MCCUNN-MILLER`
}

This article describes an alternative dispute resolution method and the specific implementation of this procedure in a recent oil pipeline contamination incident. The event, known as the "Rangeland Incident," involved the sale of contaminated crude oil by Alberta oil producers to Montana refiners. The dispute resolution method described in this article involves two phases. The first phase involves the settlement of grievances between the Alberta suppliers and the Montana refiners, whereas the second addresses liability among the parties allegedly responsible for the oil contamination. Included in the article is a model Contribution Agreement form that is the basis of the described resolution method.

\section{TABLE OF CONTENTS}

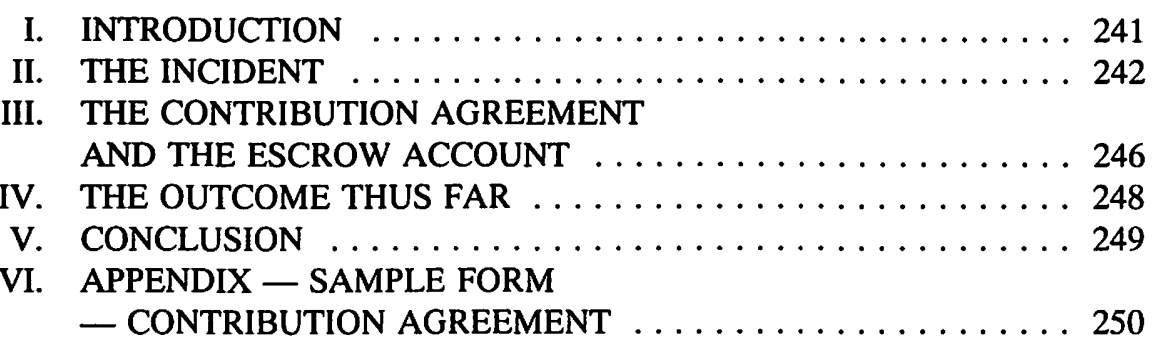

\section{INTRODUCTION}

An incident causing the contamination of 300,000 barrels of crude oil could have resulted in the virtual shutdown of a pipeline, direct economic loss to the refiners that relied on the crude oil and costly litigation amongst the suppliers. The fact that it did not was the result of cooperative action by all of the parties involved to minimize damage, mitigate loss and restore operations without the delay of protracted legal action. The focus of this article is this alternative response to the management of a crude oil contamination incident. Specifically, it will outline the structure which evolved as affected parties developed a plan of action following notification of crude oil contamination which could have shut down supply and transportation for four refiners. This review will outline a case study of the Rangeland crude oil contamination which occurred in January of 1993. The parties involved in that contamination problem joined in an unprecedented, cooperative industry effort which quickly restored supply and developed cost-effective settlement options. These efforts could easily have been stymied by a more conventional strategy which would have dictated triggering formal legal action.

Barrister and Solicitor, General Counsel and Secretary for the Alberta Petroleum Marketing Commission. The author wishes to thank Scott R. Miller, Barrister and Solicitor, Senior Regulatory Counsel for Petro-Canada, for his help in the preparation of this review. The views expressed in this article are the views of the author alone and are not necessarily the views of the Alberta Petroleum Marketing Commission or the parties involved. 
The Rangeland response is of interest as it demonstrates that alternative dispute resolution and cooperation among affected parties may ultimately prove to be preferable to traditional solutions. Early indications suggest that this method has been successful; however, it is important to note that these observations are preliminary. The first phase of the Rangeland response concluded upon the successful completion of a settlement between the Montana refiners and the Rangeland light crude oil suppliers (the "Rangeland Suppliers" or "Suppliers"). The second phase, concerning settlement discussions addressing liability and the apportionment of liability, continue among the parties allegedly responsible for the contamination. Parties are therefore cautioned to revisit the Rangeland response at a later date in order to more accurately gauge its ultimate success.

The Rangeland response is also of interest because of the increased frequency of contamination problems associated with Alberta crude supply. There have been a number of incidents this past winter, involving organic chloride contamination (including organic halides) of product streams in crude oil pipelines. The Rangeland contamination of January 1993 was followed in February 1993 by a smaller scale contamination incident involving contaminated crude oil shipments on Koch Oil's Valley Pipeline system. In March 1993 there was an organic chloride contamination concern raised with regard to certain Caroline condensate movements on the Interprovincial Pipeline system. While it would be an exaggeration to say that organic chloride contamination is a constant problem, it has become apparent that it is an ongoing concern requiring steady vigilance. Given the serious consequences of such contamination incidents, this may be an opportune time to review operational practices at the well and battery site, contracting practices, pipeline tariffs and guidelines, insurance coverage, the frequency and nature of product testing and alternative response mechanisms such as that utilized in the Rangeland response.

\section{THE INCIDENT}

In early February 1993, the Alberta Petroleum Marketing Commission ("APMC"), Northridge Petroleum Marketing Inc., Northridge Exploration Ltd. (collectively "Northridge") and Morrison Petroleums Ltd. ("Morrison") were advised by Rangeland Pipeline Company Limited and Amoco Canada Petroleum Company Ltd. (operator of the Rangeland Pipeline) ("Rangeland" or "Amoco") that Conoco Pipe Line Company's ("Conoco Pipe Line") 24 hour lab, located at Cutbank, Montana, had detected very high levels of organic chlorides in crude oil volumes flowing off the Rangeland system into Conoco Pipe Line's Glacier system, destined for delivery to refiners in the State of Montana. Upon detection of the contamination, immediate steps were taken to segregate the contaminated crude oil and move it off the pipeline system in order to prevent further commingling and the spread of contamination to incoming linefill and other interconnecting pipeline systems. Analysis revealed that contaminated crude oil had comingled with the Rangeland light crude oil stream, potentially contaminating up to 300,000 barrels of crude oil. Nearly half of that volume had already been delivered into the Montana refinery market.

Laboratory testing undertaken by Amoco determined that the likely source of the contamination was a well site and battery operated by Morrison. Morrison had, 
unknowingly, sold to Northridge, and delivered as payment of royalty in kind to the APMC, contaminated crude production. The Morrison crude had been trucked to the Hartel truck terminal and tendered to Amoco for injection into the Rangeland system. Rangeland operates as a single shipper pipeline and therefore Amoco purchases crude tendered by the Rangeland Suppliers at the inlet to Rangeland. The Suppliers subsequently repurchase the crude at the outlet of the pipeline near Carway, Alberta. Amoco, unknowingly, therefore sold the contaminated Rangeland stream to thirteen Rangeland suppliers at the outlet to Rangeland. The Rangeland suppliers then sold the crude, directly or via a series of contracts, to the eventual customers, comprised of four Montana refiners, including Conoco Inc., Farmers Union Central Exchange Incorporated ("CENEX"), Montana Refining Company and Exxon Supply Company (the "Montana Refiners" or "Refiners").

As the details of the contamination incident began to unfold, the key parties came together to address the immediate concerns of containment of contaminated crude oil and mitigation of damage. Contaminated crude oil diverted into storage included:

Hartel truck terminal (Alberta)

Pincher Creek station (Alberta)

Cutbank/Roundup (Montana) approx. $15,000 \mathrm{bbls}$ at $3.0 \mathrm{ppm}$

approx. 45,000 bbls at $117.0 \mathrm{ppm}$

approx. 48,000 bbls at $3.3 \mathrm{ppm}$

approx. 48,000 bbls at $5.3 \mathrm{ppm}$

approx. $48,000 \mathrm{bbls}$ at $11.3 \mathrm{ppm}$

Decisions had to be made concerning processing, alternate storage or disposal of the crude oil. Time was of the essence in dealing with the Montana refiners and the pipeline companies as their operations were severely and adversely affected by high volumes of contaminated crude oil. Any crude oil testing in excess of 1.5 parts per million (ppm) of organic chlorides would likely cause Conoco Pipe line to shut in the connecting carrier, Rangeland Pipeline. Unavailability of storage space throughout the transportation system reduced operational flexibility and pipeline "tightlining" raised a concern of reduced throughput levels. The Refiners had to lower their run rates and could conceivably have been starved for feedstock due both to reduced supply and due to the fact that all available refiner storage that normally could have housed emergency supply, was occupied by the diverted contaminated crude oil. Pipeline shut-in would leave Refiners with operating inventory for less than three days' production. There was a further concern that closure of the Hartel truck terminal and the Pincher Creek station on the Rangeland system, due to the necessary storage of contaminated crude oil, would impede all further product movements on the Rangeland system.

Although the source of the contamination was quickly identified, the precise nature of the contaminant was much more difficult to pinpoint. Concern centered on the fact that Morrison had used an experimental drilling fluid to drill an underbalanced horizontal well. The drilling fluid had been weighted with a fire retardant, (Trisol Fire Retardant or "TFR"), and injected into the well. It is thought that a pressure "kick" during drilling had forced some of the TFR into the formation. It was later confirmed through chemical analysis that the TFR was the likely source of the organic chlorides. The TFR had been purchased by Canadian Fluid Systems ("CFS") from Trisol Inc. ("Trisol") and resold to 
Morrison. All of these parties were operating under the belief that TFR was a refinerfriendly product which could be resold as part of crude oil production.

Once the composition of the contaminant was known, the Refiners were able to consult with their chemical and metallurgical experts to evaluate their ability to refine the contaminated crude and to assess the resulting damage or refining cost, on a per barrel basis, for processing the contaminated crude oil. Pipeline specifications supplied for each of the crude oil carriers involved clearly specified that the crude oil supplied must be free of organic chlorides, as organic chlorides have a cumulative effect on refinery operations and can be highly corrosive to the metallurgy of the refinery. When organic chlorides come in contact with moisture and are heated to a certain level, as during desulfurization in the refining process, they decompose to form hydrochloric acid which is highly corrosive to carbon steel equipment. Although some refining operations can handle organic chlorides, the Montana refineries were not equipped to process such material. As a result, the Refiners had serious concerns about the use of the contaminated crude including high cost associated with corrosion of refinery equipment, resulting in down-time and loss of equipment, as well as the increased potential for explosions and fires.

The APMC gathers crude from more than 1,000 receipt points throughout the province for delivery to feeder pipelines to transport the crude to local refineries or for injection into extra-provincial pipeline systems. It was due to its extensive province-wide involvement in the crude oil industry, and because the APMC, as agent for the Government of Alberta, takes payment of crude oil royalty in kind that the APMC was unfortunately destined to become one of the first innocent aggrieved parties as a result of the Rangeland crude oil contamination incident. Although the APMC, like Northridge and Rangeland, was not responsible for the initial contamination incident at the Morrison-operated well site and battery, the APMC and Northridge unfortunately became the first links in an extensive chain of aggrieved parties stretching from Alberta into Montana.

The magnitude of the contamination, the volume of the contaminated crude and the number of affected parties led the APMC to conclude that this incident could cause major disruptions in its business activities both in Alberta and in the U.S. The APMC and others concluded that parties had to act swiftly to contain and mitigate the damages associated with the contamination incident in order to cap damages experienced south of the border and to move forward with an early resumption of normal supply, transportation and refining activities. The APMC therefore undertook to become the designated administrator, as well as one of the contributors, of a fund designed to rapidly provide settlement dollars to innocent aggrieved parties because it was persuaded that it was the most efficient and cost-effective way to handle this matter in a manner that would benefit industry as a whole. Just as pollution response funds have been established in relation to oil spills and pollution incidents in order to resolve initial financial needs in an expedited manner while preserving future action, a contamination fund was developed to meet this incident.

Shortly following quarantine of the suspect well and segregation of the contaminated crude oil volumes, the Rangeland compensation "pool" was created in order to establish 
the financial ability to quickly conclude a settlement with the Refiners. There was a valid concern that failure to achieve a settlement prior to industry payday in the U.S. (generally the twentieth day of the month following the delivery month) would likely trigger a multiplicity of legal actions moving in a domino effect up the possible contractual and liability chain from the four Montana refiners, through thirteen Rangeland crude oil suppliers, other contract parties, Conoco Pipe Line, Rangeland Pipeline, APMC, Northridge, Morrison, Trisol, Canadian Fluid Systems, Ethyl Corp. (a U.S. supplier of some of the components of TFR) and potentially reaching even to the Alberta Research Council ("ARC"). The ARC was party to a royalty agreement with Trisol concerning the sale of TFR and had allegedly tested TFR.

This group, the Rangeland "Pool Participants", comprised of APMC, Northridge, Amoco (including the Rangeland and Aurora Pipelines), Morrison, Trisol and CFS, joined in a unique cooperative effort to mitigate and cap damages and reduce the number of aggrieved parties involved in the dispute concerning liability. The primary focus of this group was to take essential mitigative steps, as soon as possible, while reserving any discussion of liability for a later date. Given the number of aggrieved parties in this incident, there was a concern that parties would be unable to achieve a settlement within the critical "pay-day" time frame which would result in increased costs. Other motivating factors providing impetus for the formation of the Rangeland Pool included the ability to respond to the Refiners' settlement offer in a timely fashion, thereby avoiding potentially higher damage costs (e.g. loss of costly refinery equipment, refinery shutdown, cost of replacement feedstock, economic loss, etc.), a reduction in the number of parties directly involved in settlement discussions and the ability to confer and make decisions on the salvage or disposal of the Canadian volumes which were impeding movements on Rangeland. It was also important to effectively manage the potential problems south of the border, because it was perceived that those settlement negotiations could set a precedent for the discussions and actions within Alberta.

The vehicle for this joint effort was a formal contribution agreement (the "Contribution Agreement") among the Pool Participants outlining the terms of their arrangement and providing for the creation of a fund held in a trust account (the "Escrow Account"). The Escrow Account was funded by the Pool Participants, and allowed the Pool to compensate Rangeland shippers for the revenue shortfall that would be experienced as a result of the discounted price paid for the contaminated oil due to the Refiners' damage assessment and to compensate Amoco for the contaminated crude oil stranded in Rangeland's possession. While the initial response of some legal counsel involved was that there should be no financial commitment to assist in the resolution of an incident for which their company had no legal liability, they were ultimately persuaded that there was a substantial benefit in facilitating the mitigation of damages, reducing the number of parties involved in the liability dispute and providing for the early resumption of normal business activities and relationships. Parties were mindful that potential damages could be very high and that delay would exacerbate the problem while early resumption of normal business activities would reduce the potential of loss to all parties. 


\section{THE CONTRIBUTION AGREEMENT AND THE ESCROW ACCOUNT}

At the behest of the other Pool Participants, the APMC agreed to set up and administer the Escrow Account and to negotiate and coordinate general releases amongst the Pool Participants, the Montana Refiners and the Rangeland Suppliers. By achieving an early settlement with the Montana Refiners, and providing for payment to the Rangeland Suppliers, equivalent to the discounted damage amount negotiated with the refiner customers, the Pool Participants effectively avoided several potential lawsuits, achieved reasonable certainty in limiting the scope of damages, reduced the number of parties involved in the dispute and moved most of the remaining concerns up the contract and liability chain into the jurisdiction of Alberta.

While the APMC administered and coordinated the Escrow Account, and negotiated releases among two dozen affected parties, Northridge, in consultation with the Pool Participants, prepared the Contribution Agreement which defined the terms of the pool arrangement and outlined the handling of the funds contained in the Escrow Account. Attached as an appendix to this article is an example of a form of contribution agreement. Those Rangeland light crude oil suppliers that were prepared to execute a general release in favour of the Pool and a general release in favour of the Montana Refiners could invoice the APMC directly for the amount of damages assessed by Refiners through negotiation and receive payment of the discounted amount directly from the Escrow Account.

The APMC, as administrator of the Escrow Account, notified all of the Rangeland shippers, just prior to the industry pay-day in the U.S. for January deliveries, that in the interest of achieving a cost-effective resolution for the processing of, and the payment for, contaminated crude delivered to the Montana refiners, the Pool Participants had joined together to address issues of common interest. The Pool agreed amongst themselves, and without prejudice to any subsequent rights or liabilities, to contribute monies on an equal share basis to the Escrow Account. One Pool Participant did not have the financial means to contribute its proportionate share, however, it was agreed that their participation was essential with a view to foreclosing on all potential action through the execution of a single general release and, therefore, their contribution was set at the nominal amount of $\$ 10.00$.

Participation in the Pool, and any actions taken by the Pool Participants, did not act as an admission or an attribution of any liability in regard to the contamination issue. An express disclaimer in this regard is contained in the Contribution Agreement. Similarly, the offer of payment by the Pool Participants to the Rangeland Suppliers was not an admission of any liability but, rather, represented a genuine attempt, undertaken in good faith and on a cooperative basis, by the Pool Participants to facilitate resolution of the problem and resumption of normal business operations.

Payment to a Rangeland Supplier by the Pool was conditional upon the Supplier (i) executing a general release in favour of the Pool Participants, and (ii) obtaining a release agreeable to the Pool Participants from each of the Montana Refiner customers. In addition, the Pool Participants had negotiated and obtained from each of the Montana 
Refiners, an appropriate general release. Note that there were no third party indemnifications.

Under the terms of the Contribution Agreement, the Pool Participants, contributed approximately $\$ 2.7$ million into the Escrow Account. This amount was calculated in order to cover the aggregate of payments to the Rangeland Suppliers and payment to Amoco as pipeline operator. This amount was capped at the market value stipulated in the Contribution Agreement for the actual purchase cost incurred by Amoco to acquire the contaminated crude oil volumes at the various Rangeland inlets. All payments from the Escrow Account had to be approved by a unanimous decision of all Pool Participants.

Notwithstanding the reimbursement to Amoco from the Escrow Account for the agreed market value of the Canadian contaminated crude oil volumes, the Contribution Agreement specifically provided that title, possession and risk associated with those volumes would remain with Amoco. Should Amoco subsequently realize some form of payment or credit for the contaminated crude oil (e.g. sales into an acceptable market), the monies, defined as the mitigating amount, would be held in trust by Amoco on behalf of the Pool Participants and thereafter distributed to Pool Participants on the basis of their percentage share of the fund.

Pool Participants and their respective insurers shared a common concern that general releases be obtained from all the appropriate parties. The requisite releases included:

1. a release from each of the Refiners, in favour of the Pool Participants;

2. a release from each of the Refiners, in favour of the Rangeland Suppliers, collectively;

3. a release from each Supplier, in favour of the Pool Participants; and

4. a release from each Supplier, in favour of its respective Refiner customer.

Participants, Refiners and Suppliers were advised to seek independent legal advice as to the substance of proposed releases and the advisability of executing them.

A further key provision in the Contribution Agreement is the disclaimer of liability clause which specifically states that the contribution of monies by each of the Pool Participants is not an assumption nor an admission of liability in regard to the contamination of crude oil on the Rangeland Pipeline system, the Aurora Pipeline System or the Glacier Pipeline system. The Pool Participants preserved any and all rights of action and rights of defence, in law and equity, however associated with or arising out of the contamination of the crude oil, including the right to seek recovery from and to defend against actions by any or all of the other Pool Participants. The Contribution Agreement also contained a "motherhood" statement to the effect that the Pool Participants agreed to negotiate in good faith in order to resolve issues of liability on an expeditious basis and if a Pool Participant is found to be liable, either by virtue of an agreement to accept liability or by virtue of a final judicial decision, then that participant would ensure that the payment of monies associated with the liability that it assumed or was assessed would be made on an expeditious basis. 
Once it is determined or agreed that one or more of the Pool Participants does not have liability in respect of the contamination incident, then the remaining liable Pool Participants shall reimburse the innocent participant for its contribution, with interest, as stipulated in the Contribution Agreement.

\section{THE OUTCOME THUS FAR}

All of the U.S. crude oil volumes have now been processed by Refiners employing specific mitigative measures designed to reduce corrosion. The only remaining cost to be addressed, emanating from a U.S. entity, relate to the damages, if any, suffered by Conoco Pipeline. During settlement discussions with Refiners, there were concurrent discussions with Conoco Pipeline. The pipeline preferred to track its costs as they were incurred and indicated that it would decide at a later date whether to proceed with any claim for damages.

The Canadian crude oil volumes at Hartel, Alberta were trucked to storage in Legend, Alberta. The majority of the Pincher Creek volumes remain in storage at that location though some of that volume has now been shipped by rail car to a refining operation in Utah that can process the contaminated crude. Due to the higher contamination levels detected in the remaining Canadian volumes, there is a reduced likelihood of salvaging the same value for the contaminated crude. Potentially, there may be no market value for some of the crude oil and indeed there will be costs associated with its safe disposal as well as transportation and tank, truck and rail car cleaning costs.

All of the Rangeland Suppliers affected by the contamination incident have invoiced the APMC and received payment from the Escrow Account. The Escrow Account was wound up in early April and the excess funds were returned, on a pro-rata basis determined by contribution, to the Pool Participants.

The first settlement conference to resolve the liability issues took place two months following the incident and included Pool Participants, their insurers and the ARC. The innocent Pool Participants expect to receive reimbursement of their contribution to the Escrow Account with a minimum of delay.

In the month following the Rangeland contamination, there was a similar, though far less extensive, contamination incident on the Valley Pipeline system involving the same contaminant. Parties were able to rely on the model response developed for the Rangeland contamination to assist in addressing that problem as well. Although the financial impact did not require a jointly funded trust account, as in Rangeland, a similar process was employed whereby primarily one party and its insurer funded a settlement with the affected Montana refiners and provided compensation to aggrieved crude oil suppliers on a without prejudice basis and without assuming liability. The latter was accomplished through the purchase of the contaminated crude oil from each supplier. The contributors executed a contribution agreement confirming this arrangement. Matters were able to proceed quickly because refiners and their legal counsel were knowledgeable about damages and familiar with the issues, the release documents and the payment procedure. Also, as this incident involved a substantially smaller volume of contaminated crude oil 
delivered into Montana, an early settlement was negotiated with refiners who, in turn, agreed not to reduce payment to their Rangeland suppliers.

\section{CONCLUSION}

These incidents have greatly sensitized industry to the problem of crude oil contamination and the associated costs arising due to damage, delay and economic loss. Most producers would still consider it financially and operationally impossible to test all crude production at the well site, however, other measures may be required to reduce loss due to contamination. Just as pipelines should consider improved testing measures, which would provide early detection of contamination, producers should review matters such as security at battery and well sites, production practices, and dissemination of critical environmental and crude oil quality information, in an effort to monitor all aspects of an operation, which could ultimately have an impact on a contamination incident. The Crown is currently reviewing its legislation and is considering the issue of crude oil quality specification in relation to crude oil delivered to the Crown as payment of royalty in kind. In the wake of recent contamination concerns in regard to certain early shipments of Caroline condensate on the Interprovincial Pipeline system, some parties have raised a concern respecting the accuracy of the traditional ASTM test in detecting low levels of organic chlorides (e.g. $1 \mathrm{ppm}$ ) and have therefore challenged the appropriateness of zero tolerance for organic chlorides as specified in most carrier tariffs.

These and other contamination issues will continue to be the source of debate. If nothing else, recent experiences should cause legal counsel to review the purchase and sale contracts utilized by their clients, and pipeline terms and conditions of transportation, with a view to assessing the full scope of their clients' obligations and warranties in respect of off-specification crude oil. As well, counsel should be aware of alternative dispute resolution methods, such as the Rangeland Pool, in order to act quickly and with confidence to provide a mechanism to resolve those issues that can be dealt with expeditiously and thereby reduce overall cost and damages to the benefit of all parties. Cooperation is the key to innovative solutions such as the Rangeland Pool and awareness and understanding are the keys to cooperation. 


\section{APPENDIX}

\section{SAMPLE FORM — CONTRIBUTION AGREEMENT}

This Agreement is made with full force and effect on

AMONG:

ALBERTA PETROLEUM MARKETING COMMISSION, a body incorporated pursuant to the Petroleum Marketing Act of Alberta R.S.A. 1980 c. P-5 and having offices in the City of Calgary, in the Province of Alberta (hereinafter the "APMC")

PARTY OF THE FIRST PART

-and-

ALPHA OIL COMPANY LTD., a body corporate having offices in the City of Calgary, in the Province of Alberta (hereinafter "Alpha")

PARTY OF THE SECOND PART

-and-

TANGO EXPLORATION LTD., a body corporate having offices in the City of Calgary, in the Province of Alberta (hereinafter "Tango")

PARTY OF THE THIRD PART

-and-

BETA PETROLEUMS LTD., a body corporate having offices in the City of Calgary, in the Province of Alberta (hereinafter "Beta")

\section{PARTY OF THE FOURTH PART}

WHEREAS certain identified volumes of crude oil on the ABC Pipeline System and the XYZ Pipeline System have been contaminated by Halides;

AND WHEREAS the Participants have worked and continue to work in good faith, in a collective and cooperative effort but on a without prejudice basis, to minimize the damages associated with said contamination;

AND WHEREAS, consistent with the said cooperative and good faith efforts, the Participants believe that the damages associated with the contamination may be reduced and minimized through the contribution by each of the Participants of monies into an Escrow Account, to provide for the funding of the expenditures contemplated herein; 
NOW THEREFORE, for good and valuable consideration, the receipt and sufficiency of which is hereby specifically acknowledged, the Participants agree that the following terms and conditions set forth their agreement to participate in the funding of the said Escrow Account:

1.00 Definitions:

1.01 The following words and phrases shall adopt and have ascribed thereto the following meanings:

(a) "Agreed Market Value of the Canadian Crude Volumes" shall mean and have ascribed thereto the definition provided for in Subsection 2.04(b) hereof;

(b) "Canadian Crude Volumes" means those volumes of crude oil that are estimated to be in aggregate barrels, and are currently in storage on the $A B C$ Pipeline System and in tankage at and that are contaminated with Halides;

(c) "Dollar Contribution" shall mean the sum of money set forth in Section 2.01 hereof that each Participant shall contribute to the Escrow Account;

(d) "Escrow Account" shall mean a trust account established and administered by APMC to receive the payment of monies by each of the Participants as contemplated in Section 2.01 hereof;

(e) "ABC Pipeline System" shall mean the system of crude oil pipelines and storage facilities that runs from currently operated by to , and that is

(f) "Halides" shall mean an organic compound containing one or more of the non-metallic elements of fluorine, chlorine, bromine, iodine and astatine;

(g) "TTT Truck Terminal" shall mean the truck terminal and storage facility located at and currently operated by , or its designate;

(h) "Participants" shall mean collectively all of the parties to this Agreement;

(i) "Payment Date" shall mean 12:00 o'clock noon Mountain Standard Time on

(j) "XYZ Pipeline System" means the system of crude oil pipelines and storage facilities that runs from to , and that is currently operated by Alpha, or its designates; 
(k) "Refiners" means collectively and in their capacity as operators of crude oil refineries located ; and

(1) "Suppliers" means collectively light crude oil to the Refiners.

in their capacity as sellers of

2.00 Escrow Account:

2.01 An "Escrow Account" in the sum of and funded by the Participants on the following basis: (Cdn.) shall be established

$\begin{array}{ll}\text { Dollar } & \text { Percent of } \\ \text { Contribution } & \text { Escrow } \\ \text { (Cdn.) } & \text { Account* }\end{array}$

Company

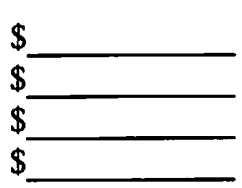

APMC

Alpha

Tango

Beta

(*Rounded to the nearest two decimal points.)

2.02 Each Participant shall pay its Dollar Contribution to the APMC on the Payment Date.

2.03 (a) The APMC shall establish and maintain the Escrow Account for the benefit of the Participants, and will deposit each Dollar Contribution received to the Escrow Account; and

(b) The APMC will be entitled to recover from the Escrow Account all third party, out of pocket expenditures that are reasonably incurred by the APMC in the establishment, maintenance and operation of the Escrow Account.

2.04 Upon receipt by the APMC of executed releases referred to in Section 4 hereof, payments shall be made out of the Escrow Account to cover:

(a) the shortfall in payments that the Suppliers would ordinarily receive on 1993 from one or more of the Refiners, that arise as a result of a portion of the crude oil deliveries from the XYZ Pipeline System during 1993 having been contaminated by Halides, and damages having been paid to the Refiners by the Suppliers as a result. It is anticipated that these aggregate payments will be made from the Escrow Account to the Suppliers on or about , 1993 and shall approximate $\$$ (Cdn.); 
(b) a payment to Alpha on or about 1993 of a sum of money equal to the actual purchase cost that was incurred by Alpha to acquire the Canadian Crude Volumes at the applicable inlet(s) to the XYZ Pipeline System, provided that such payment shall not exceed $\$$ Canadian Crude Volumes");

(Cdn.) (the "Agreed Market Value of the

(c) any nominal payments that are required in order to obtain the releases from the Refiners and Conoco Inc. as contemplated in Subsection 4.01(a) hereof; and

(d) any third party, out of pocket expenditures reasonably incurred by the APMC in the establishment, maintenance and operation of the Escrow Account.

2.05 All payments out of the Escrow Account shall be approved, in writing, by a unanimous decision of all of the Participants, except for which shall have no vote in this regard. Except as specifically set forth in Section 2.04 above, no other payments shall be made out of the Escrow Account.

2.06 If after having paid out those amounts specified in Section 2.04 above, and/or after having made reasonable provisions therefore, there are excess funds in the Escrow Account, the APMC shall promptly distribute said excess to the Participants in proportion to their respective Dollar Contributions.

3.00 Title, Risk and Possession of Canadian Crude Volumes:

3.01 Notwithstanding reimbursement of Alpha from the Escrow Account for the Agreed Market Value of the Canadian Crude Volumes in a good faith effort by the Participants to alleviate the financial costs that would otherwise have been incurred by Alpha, title, possession and all risks associated with the Canadian Crude Volumes will remain with Alpha.

3.02 If a market is found for the Canadian Crude Volumes, and this market provides either a credit amount or a partial payment to Alpha for the value of said crude oil (the credit amount or the sum of the monies so received being hereinafter defined as the "Mitigating Amount"), Alpha shall hold the Mitigating Amount in trust on behalf of the Participants. Accordingly, Alpha shall, upon its receipt of the Mitigating Amount, immediately pay to each Participant the result obtained by multiplying the Mitigating Amount by the Percentage of the Fund that is assigned to that Participant under the provisions of Section 2.01 above.

3.03 Nothing contained in this Section 3.00 shall act as a release of the Participants from any claims, actions or demands by Alpha for any damages, costs and expenses incurred by Alpha in respect to the Canadian Crude Volumes that are not reimbursed to Alpha pursuant to Section 2.04 . 
3.04 The Participants agree that any payments pursuant to Sections 2.01 and 2.04 herein are based on the understanding that the Goods and Services Tax ("GST") is not applicable. Should it subsequently be determined by Revenue Canada that GST is applicable to any or all of the transactions described above, the Participants hereby agree to compensate the APMC, in proportion to their respective monetary contributions, for the amount of any GST, interest and penalties assessed by Revenue Canada for which APMC may be found liable in its capacity as trustee of the Escrow Account.

4.00 Negotiation of Releases:

4.01 The APMC shall endeavour to provide, to the appropriate parties, the following draft releases:

(a) a draft general release from each of the Refiners, in favour of the Participants, that is substantially in the form attached as Schedule " $\mathrm{A}$ " hereto,

(b) a draft general release from each of the Refiners, in favour of the Suppliers, that is substantially in the form attached as Schedule "B" hereto,

(c) a draft general release from each of the Suppliers, in favour of the Participants, that is substantially in the form attached as Schedule " $\mathrm{C}$ " hereto; and

(d) a draft general release from each Supplier, in favour of its respective Refiner customer, that is substantially in the form attached as Schedule "D" hereto.

4.02 The Participants acknowledge that the provision of draft releases by the APMC to all appropriate parties is done solely to coordinate aspects relating to the administration of the Escrow Account, and the Participants, Refiners and Suppliers must each seek independent legal advice as to the substance of the draft releases and the advisability of executing said releases.

5.00 Disclaimer of Liabilities:

5.01 It is specifically acknowledged that the contribution of monies and receipt by each of the Participants as contemplated in this Agreement is done on a without prejudice basis, and on the express understanding that each of the individual Participants:

(a) is not thereby assuming or admitting to liability associated with the contamination of crude oil on the ABC Pipeline System and/or the XYZ Pipeline System; and 
(b) is preserving any and all rights of action and rights of defence howsoever associated with or arising out of the contaminated crude oil, including without limitation to the generality of the foregoing, the right to seek recovery from and/or to defend against actions by any or all of the other Participants.

6.00 Negotiations Amongst Participants:

6.01 While the Participants recognize that the parties ultimately responsible for the contamination of the crude oil on the ABC Pipeline System and the XYZ Pipeline System may not include or be limited to the Participants under this Contribution Agreement, and that there is the possibility that issues of liability may be determined or resolved through litigation, the Participants agree to negotiate in good faith to resolve issues of liability on an expeditious basis, and, if a Participant is deemed to have liability whether by virtue of its agreement to accept said liability or by virtue of a final judicial decision, said Participant(s) will ensure that the payments of monies associated with the liabilities that it assumes are made on an expeditious basis.

7.00 Interest Payments to Innocent Participants:

7.01 In the event that it is ultimately determined that one or more of the Participants does not have liability in relation to the contamination (hereinafter defined as the "Innocent Participants"), and one or more of the other Participants hereunder must make payments of money in settlement of its liabilities with respect to the contaminated crude oil (hereinafter defined as the "Liable Participants"), then, in addition to any other amounts that are due by the Liable Participants to the Innocent Participants in respect of said liability, the Liable Participants shall also provide the Innocent Participants with interest on the payment amount, calculated from the date hereof and compounded semi-annually on arrears until the date payment is received by the Innocent Participants, whether before or after judgment, calculated on the basis of the prime rate of interest that is charged by the Main Calgary Branch of the Toronto Dominion Bank to its most creditworthy customers, during the relevant periods in time, plus one (1) percent.

7.02 The Liable Participants shall ensure that payments are made to the Innocent Participants, as said terms are defined in Section 7.01 above, as soon as possible after there has been a determination of liability, whether by virtue of an agreement to accept liability or by virtue of a final judicial decision.

\section{$8.00 \quad$ General:}

8.01 This Agreement shall be governed by the laws of the Province of Alberta and the laws of Canada applicable therein, and the parties accept and attorn to the exclusive jurisdiction of the courts of the Province of Alberta and the courts 
of appeal therefrom for the purposes of the interpretation, construction and enforcement of this Agreement.

8.02 No amendment nor variation of this Agreement shall be effective or binding upon the parties unless it is set forth in writing and has been duly executed on behalf of each of the parties by its respective proper officers or authorized representatives in that behalf.

8.03 This Agreement constitutes the entire agreement between the parties relative to the matters herein provided or contemplated and there are no other representations, warranties, covenants or agreements in respect thereto.

8.04 The parties shall from time to time and at all times hereafter do all such further acts and execute and deliver all such further deeds and documents as shall be reasonably required in order to fully perform and to more effectively implement and carry out the terms of this Agreement.

8.05 This Agreement may be executed in counterpart and when so executed shall have the same effect as if all parties had executed the same document. Each party executing a counterpart of this Agreement shall deliver one executed copy of such counterpart to the other parties.

8.06 Time shall be of the essence herein.

8.07 All liabilities of the parties under this Agreement are several and not joint.

IN WITNESS WHEREOF the parties hereto have duly executed and delivered this Agreement under the signature of their respective corporate officers, duly authorized in that regard, as of the 1st day of March, 1993.

\section{ALBERTA PETROLEUM MARKETING COMMISSION}

Per:

ALPHA OIL COMPANY LTD..

Per:

TANGO EXPLORATION LTD.

Per:

BETA PETROLEUMS LTD.

Per: 
ALBERTA RESEARCH COUNCIL
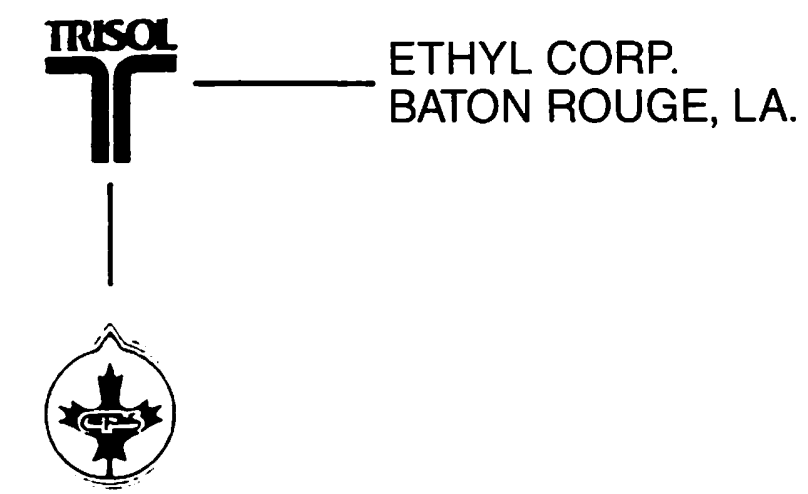

CANADIAN FLUID

SYSTEMS LTD.
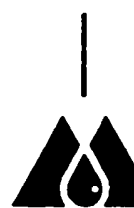

MORRISON

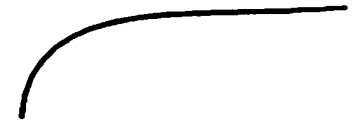

NORTHRIDGE

NORTHRIDGE PETROLEUM MARKETING INC
ETHYL CORP.
BATON ROUGE, LA.
Alberta

PETROLEUM MARKETING COMMISSION

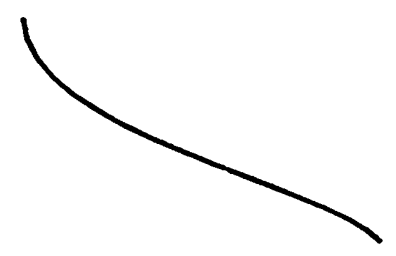

HARTEL
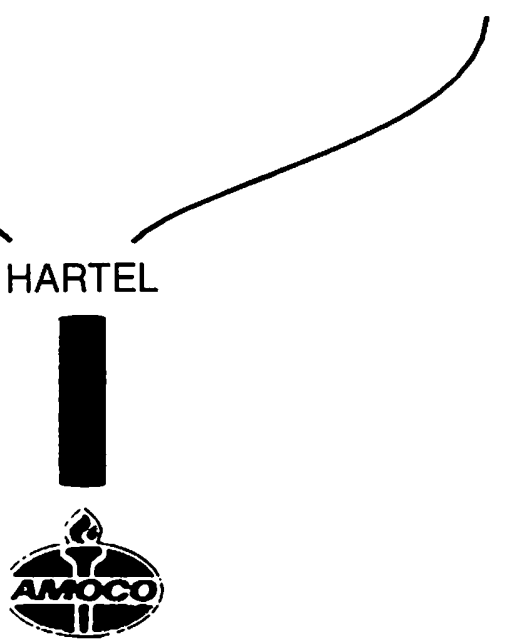

RANGELAND

SYSTEM 


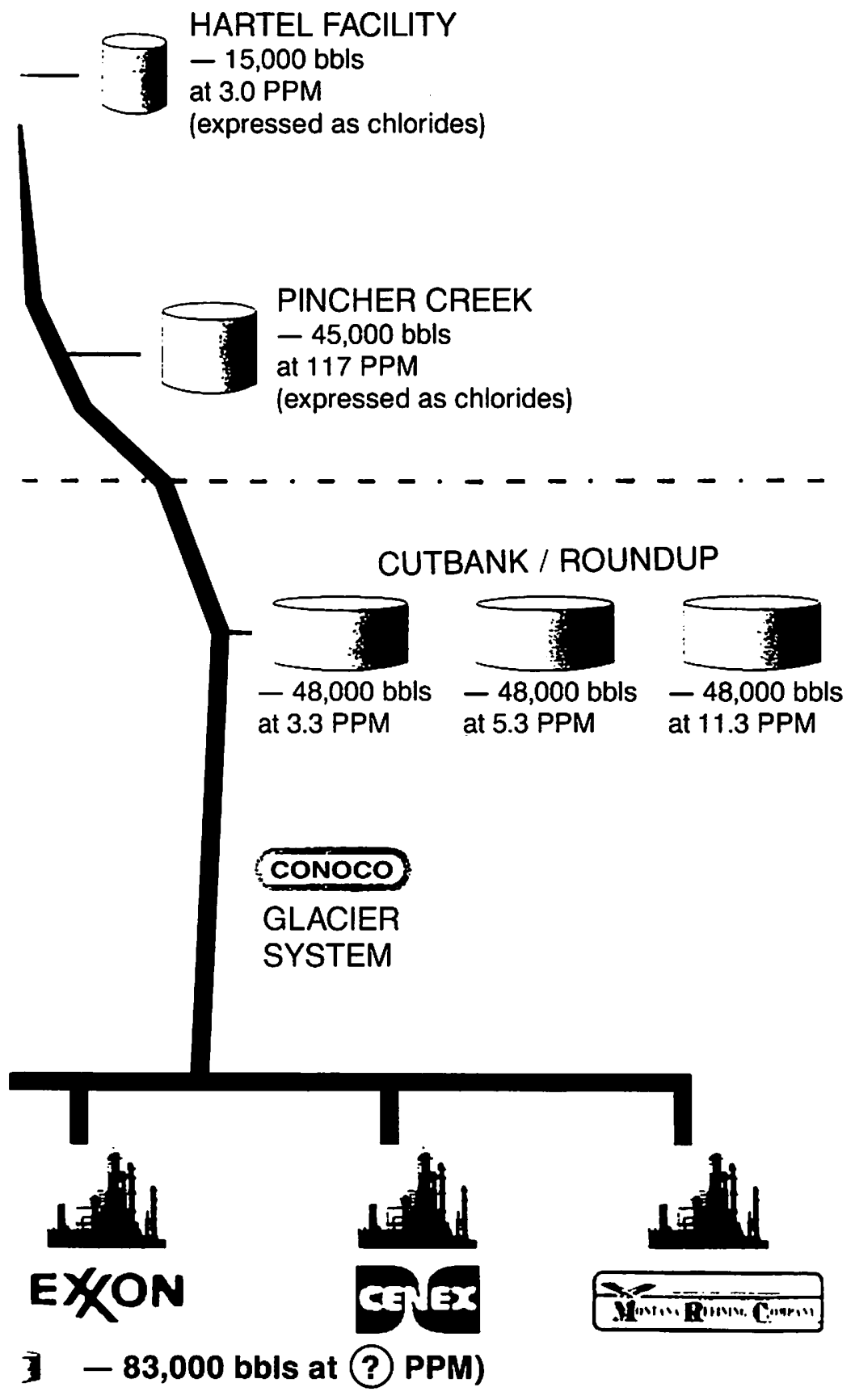

